\title{
ANALISIS PENGARUH NILAI PELANGGAN DAN CITRA MEREK TERHADAP KEPUASAN PELANGGAN PADA RUMAH MAKAN LAMUN OMBAK DI KOTA PADANG
}

\author{
Juli Zarman, Aminar Sutra Dewi \\ Sekolah Tinggi Ilmu Ekonomi KBP \\ julizarman164@gmail.com
}

\begin{abstract}
This study was conducted to examine the effect of customer value and brand image of the value of customer satisfaction with home eating seagrass meadow waves in the city. the population used in this study food consumers seagrass waves in town padang.teknik sampling method used is judgemen sampling criteria have been a food consumers seagrass meadow waves in the city. The number of samples preformance this study of 100 respondents, which is based on the view roscoe quoted sekaran (2006). Based on the results of studies using multiple linear regression analysis on the influence of customer value and brand image on customer satisfaction home eating seagrass waves. It can be concluded that the two independent variables have a significant influence on customer satisfaction in choosing where to eat. Of the two independent variables are the most dominant influence on customer satisfaction home eating seagrass waves is customer value.
\end{abstract}

Keywords : Customer Value, Brand Image, Customer Satisfaction

\section{PENDAHALUAN}

Kepuasan pelanggan merupakan suatu tingkatan dimana kebutuhan, keinginan dan harapan dari pelanggan dapat terpenuhi yang akan mengakibatkan terjadinya pembelian ulang atau kesetiaan yang berlanjut. Rumah makan lamun ombak adalah salah satu rumah makan yang menawarkan cita rasa yang baragam yaitu dari kuliner nusantara yang ada di kota padang apabila anda telah berada di kota padang banyak menu kuliner yang bisa anda cicipi yaitu di rumah makan lamun ombak jl.khatib sulaiman padang dan juga tersedia di cabang lain nya.

Tabel 1

Jumlah Pengunjung RM. Lamun Ombak

\begin{tabular}{|l|c|rr|}
\hline Bulan & Total pengunjung Lamun Ombak & \multicolumn{2}{c|}{$\begin{array}{c}\text { Pertambahan/penurunan pengunjung } \\
\text { perbulan }\end{array}$} \\
\hline Januari & 4875 & -1878 \\
\hline Februari & 5439 & +564 \\
\hline Maret & 5682 & +243 \\
\hline April & 4945 & -737 \\
\hline Mei & 10791 & +5846 \\
\hline Juni & 9749 & -1042 \\
\hline
\end{tabular}

Berdasarkan data pengunjung pelanggan diatas menunjukkan bahwa pelanggan masih terlihat dari data pada bulan juni terjadi penurunan pengunjung 
yang sangat drastis sebesar 1042 dari 10791 menjadi 9749 disini dapat dilihat kepuasan pelanggan menurun terhadap rumah makan lamun ombak. Menyadari peran penting konsumen dan pengaruh kepuasan konsumen terhadap keuntungan, perusahaan berupaya mencari cara yang dapat meningkatkan kepuasan konsumen

Dalam menciptakan kepuasan pelanggan, perusahaan harus dapat meningkatkan nilai pelanggan (nilai pelanggan). Semakin baik penilaian dan citra pelanggan, akan semakin tinggi pula kepuasan pelanggan. Tingginya kepuasan pelanggan juga tidak lepas dari dukungan internal perusahaan, terutama dukungan dari sumber daya manusianya. Customer Value (nilai pelanggan) merupakan taksiran konsumen secara keseluruhan terhadap manfaat suatu produk berdasarkan persepsinya terhadap apa yang diterima oleh konsumen dan yang diberikan oleh produsen.

Brand image (citra merek) merupakan representasi dari keseluruhan persepsi terhadap merek dan bentuk dari informasi dan pengalaman masa lalu terhadap merek itu.

Adapun rumusan masalah pada laporan ini adalah :

1. Bagaimana pengaruh nilai pelanggan terhadap kepuasan pelanggan pada restoran lamun ombak dipadang?

2. Bagaiman pengaruh citra merek terhadap kepuasan pelanggan pada restoran lamun ombak di padang ?

Adapun tujuan penelitian yang penulis lakukan adalah untuk:

1. Untuk menganalisa pengaruh nilai pelanggan terhadap kepuasan pelanggan secara signifikan pada restoran lamun ombak di padang.

2. Untuk menganalisa pengaruh nilai pelanggan terhadap citra merek secara signifikan pada restoran lamun ombak di padang.

\section{LANDASAN TEORI}

\section{Pengertian Kepuasan Pelanggan}

Menurut Kotler dan Armstrong (2001:9),Kepuasan konsumen adalah sejauh mana anggapan kinerja produk memenuhi harapan pembeli. Bila kinerja produk lebih rendah ketimbang harapan pelanggan, maka pembelinya merasa puas atau amat gembira. Kepuasan konsumen adalah sejauh mana manfaat sebuah produk dirasakan (perceived) sesuai dengan apa yang diharapkan pelanggan (Amir, 2005). Kotler (2000) mengatakan bahwa kepuasan konsumen merupakan tingkat perasaan seseorang setelah membandingkan antara kinerja produk yang ia rasakan dengan harapannya.

\section{Pengertian Nilai Pelanggan}

Istilah nilai (value) digunakan sebagai konteks yang berbeda. Menurut Woodruff (1997:142), Customer Value adalah pilihan yang dirasakan pelanggan dan evaluasi terhadap atribut produk dan jasa, kinerja atribut dan konsekuensi yang timbul dari penggunaan produk untuk mencapai tujuan dan maksud konsumen ketika menggunakan produk. Woodruff juga mendefinisikan Customer Value sebagai persepsi pelanggan terhadap konsekuensi yang diinginkannya dari penggunaan suatu produk/jasa. 


\section{Pengertian Citra Merek}

Menurut Kootler dan Keller (2009) asosiasi pemasaran amerika mendifinisikan merek (brand) sebagai Nama, Istilah, Tanda, Symbol, Rancangan atau kombinasi dari semuanya, yang dimaksud untuk mengidetifikasi barang atau jasa penjual dan untuk mendiferensikan nya dari barang atau jasa pesaing. dengan demikian sebuah merek adalah produk atau jasa penambah dimensi yang dengan cara tertentu mendiferensikan nya dari produk atau jasa lain yang dirancang untuk memuaskan kebutuhan yang sama.

\section{Hubungan Nilai Pelanggan Terhadap Kepuasan Pelanggan}

Penelitian Balqis Diaab, (2009) Tentang Analisis Pengaruh Nilai Pelanggan Dan Citra Merek Terhadap Terhadap Kepuasan Pelanggan Dalam Meningkatkan Retensi Pelanggan (studi kasus pada gies batik pekalongan), dimana hasil penelitian terhadap pengaruh nilai pelanggan positif dan signifikan terhadap kepuasan pelanggan.

Penelitian Rahmat Hidayat, (2009) Tentang Pengaruh Kualitas Layanan,Kualitas Produk Dan Nilai Nasabah Terhadap Kepuasan Dan Loyalitas Nasabah Bank Mandiri, dimana hasil penelitian terhadap pengaruh nilai pelanggan positif dan signifikan terhadap kepuasan pelanggan.Dari beberapa penelitian di atas maka dapat ditarik hipotesis :

$\mathrm{H}_{1}$ : Diduga Nilai Pelangganberpengaruh signifikan dan positif terhadap kepuasan pelanggan

\section{Hubungan citra merek terhadap kepuasan pelanggan}

Penelitian Balqis Diaab, (2009) Tentang Analisis Pengaruh Nilai Pelanggan Dan Citra Merek Terhadap Terhadap Kepuasan Pelanggan Dalam Meningkatkan Retensi Pelanggan (studi kasus pada gies batik pekalongan), dimana hasil penelitian terhadap pengaruh nilai pelanggan positif dan signifikan terhadap kepuasan pelanggan.

Penelitian Mohammad Tambrin, (2010) tentang Pengaruh Brand Image Pelanggan Kartu Simpati Terhadap Kepuasan Mahasiswa Universitas Trunjoyo Madura, dimana hasil penelitian terhadap pengaruh nilai pelanggan positif dan signifikan terhadap kepuasan pelanggan.Dari beberapa penelitian di atas maka dapat ditarik hipotesis :

$\mathrm{H}_{2}$ : Diduga Citra merek berpengaruh signifikan dan positif terhadap kepuasan pelanggan

\section{METODE PENELITIAN \\ Uji Validitas}

Validitas berasal dari kata validity yang mempunyai arti sejauh mana ketepatan dan kecermatan suatu alat ukur dalam melakukam fungsi ukurannya (Azwar 1986). Ghozali (2009) menyatakan bahwa uji validitas digunakan untuk mengukur sah, atau valid tidaknya suatu kuesioner. Suatu kuesioner dikatakan valid jika pertanyaan pada kuesioner mampu untuk mengungkapkan sesuatu yang akan diukur oleh kuesioner tersebut.

\section{Uji Reliabilitas}

Uji reliabilitas adalah tinngkat kestabilan dari suatu alat ukur dalam mengukur suatu gejala.reliabilitas berkenaan dengan derajat kosistensi dan 
stabilitas data atau temuan. Dalam pandangan positivistik (kuantitatif), suatu data dinyatakan reliabel apabila dua atau lebih peneliti dalam objek yang sama menghasilkan data yang sama, atau peneliti sama dalam waktu yang berbeda menghasilkan data yang sama atau sekelompok data bila dipecah menjadi dua menunjukan data yang tidk berbeda (sugiyono, 2013)

Pengujian reliabilitas dalam penelitian ini dilakukan dengan menghitung besarnya cronbach's Alpha instrumen dari masing-masing variabel yang di uji, uji reliabilitas ini dilakukan terhadap pertanyaan yang telah valid. Dengan melihat nilai dari composite reliability di atas 0,60 , maka semua pernyataan dinyatakan reliabel.

\section{Analisis Deskriptif}

Merupakan proses pengolahan data yang telah didapat dari responden, data tersebut dinilai dengan pemberian skor, setelah pemberian skor data tersebut diolah dengan menggunakan rumus persentase (arikunto, 2010) sebagai berikut :

Dimana :

$$
\mathbf{P}=\frac{\text { Frekuensi }}{\text { jumlah responden }} \times 100 \%
$$

$\mathrm{P} \quad=$ persentase hasil yang diperoleh

$\mathrm{F} \quad=$ frekuensi hasil yang diperoleh

$\mathrm{N} \quad=$ jumlah responden yang dijadikan sampel

$100=$ angka tetap persentase

Untuk mendapatkan rata-rata skor masing-masing indikator dalam pertanyaan-pertanyaan yang terdapat dalam kuesioner dipakai (arikunto, 2010) rumus sebagai berikut :

Dimana: $\mathrm{Fi}=$ frekuensi

$$
\text { Rata }- \text { rata skor }=\frac{\sum \mathrm{fi} \mathrm{x} \mathrm{W}_{\mathrm{o}}}{\text { Banyak responden }(\mathrm{n})}
$$

$$
\text { Wo = bobot }
$$

Sedangkan untuk mencari tingkat pencapaian jawaban responden digunakan rumus (arikunto, 2010) sebagai berikut :

\section{Uji normalitas}

$$
\text { TCR }=\frac{\text { Rata-rata skor }}{5} \times 100
$$

Menurut ghozali (2011) Uji normalitas bertujuan untuk menguji apakah dalam model regresi, variabel pengganggu atau residual memiliki distribusi normal. Seperti diketahui bahwa uji t dan uji f mengasumsikan nilai residual mengikuti distribusi normal. Pengujian normalitas dilakukan dengan menggunakan one sample kolmogorov smirnov test. Dimana prinsip dari normalitas ditunjukan dengan tingkat signifikan $\alpha=0,05$. Dasar pengambilan keputusan dari uji normalitas ini adalah dengan melihat probabilitas asymp.sig (2tailed). Jika probabilitas asymp.sig (2-tailed) $>\alpha=0,05$. Maka residual data tersebut berdistribusi normal.

\section{Uji Multikolinearitas}

Uji multikolinearitasbertujuan untuk menguji apakah model regresi ditemukan adanya korelasi antar variabel bebas (independent variabel). Model regresi yang baik seharusnya tidak terjadi korelasi di antara variabel bebas. Jika variabel bebas saling berkorelasi, maka variabel-variabel tersebut tidak ortogonal. 
Variabel ortogonal adalah variabel bebas yang nilai korelasi antar sesama variabel bebas sama dangan nol (ghozali, 2011). Adapun cara untuk mendeteksi ada atau tidaknya multikolinearitas didalam model regresi melalui nilai tolerance dan variance inflation factor (VIP). Kedua ukuran ini menunjukan setiap variabel bebas manakah yang dijelaskan oleh variabel bebas lainnya. Dalam pengertian sederhana setiap variabel bebas menjadi variabel terikat dan di regresi terhadap variabel bebas lainnya. Nilai cut - off yang umum dipakai untuk menunjukan adanya multikolinearitas adalah nilai tolerence $<0,10$ atau sama dengan nilai VIF $>10$ (ghozali, 2011).

\section{Uji Heteroskedastisitas}

Uji heteroskedastisitas bertujuan untuk menguji apakah dalam model regresi terjadi ketidaksamaan varians dari residual suatu persamaan ke pengamatan lain. Jika varian dari residual suatu pengamatan ke pengamatan lain tetap, maka disebut homokedasititas dan jika berbeda disebut heteroskedastisitas. Sedangkan model regresi yang baik adalah jika tidak terjadinya heteroskedastisitas. Untuk mendeteksi adanya heteroskedastisitas dapat menggunakan uji gletser. Dalam uji ini apabila signifikansi $>\alpha=0,05$ atau kesalahan menolak data maka tidak terdapat gejala heteroskedastisitas, model yang baik adalah tidak terjadi heteroskedastisitas (ghozali, 2011).

\section{Analisis Regresi Linier Berganda}

Analisis regresi linier berganda digunakan unruk mengetahui ada tidak nya pengaruh variabel independent (nilai pelanggan dan citra merek) dengan variabel dependent (kepuasan pelanggan). model atau persamaan analisis regresi berganda sebagai berikut (ghozali, 2005) :

Dimana $: \mathrm{Y}=$ Kepuasan pelanggan

$$
\mathbf{Y}=\mathbf{a}+\mathbf{b}_{1} \mathbf{X}_{1}+\mathbf{b}_{2} \mathbf{X}_{2}+\mathbf{e}
$$

$\mathrm{a} \quad=$ konstanta

$\mathrm{X}_{1} \quad=$ nilai pelanggan

$\mathrm{b}_{1} \quad=$ koefisien nilai pelanggan

$\mathrm{X}_{2}=$ citra merek

$\mathrm{b}_{2} \quad=$ koefisien citra merek

$\mathrm{e} \quad=$ error/variabel pengganggu

selanjutnya dalam pengolahan data penulis akan memanfaatkan program Microsoft office excel 2007 dan SPSS (statistical program for social science).

\section{Pengujian Hipotesis}

\section{Uji Signifikan Simultan (Uji F)}

Uji F yaitu suatu uji untuk mengetahui pengaruh variabel bebas yaitu nilai pelanggan (X1), citra merek (X2) secara simultan terhadap variabel terikat yaitu kepuasan pelanggan (Y).Kriteria untuk menguji hipotesis adalah :Dengan tingkat kepercayaan sebesar $95 \%$ atau taraf signifikansi sebesar $5 \%$, maka :

1) Jika F hitung > F tabel, maka H0 ditolak, berarti masing-masing variabel bebas secara bersama-sama mempunyai pengaruh yang signifikan terhadap variabelterikat.

2) Jika F hitung < F tabel, maka H0 diterima, berarti masing-masing variabel bebas secara bersama-sama tidak mempunyai pengaruh yang signifikan terhadap variabel terikat. 


\section{Uji T}

Uji t digunakan untuk menguji signifikansi konstanta dari setiap variabel independen, apakah nilai pelanggan (X1), citra merek (X2), benar - benar berpengaruh secara parsial (terpisah) terhadap variabel dependennya yaitu kepuasan pelanggan (Y). Kriteria pengujian dengan tingkat signifikansi (a) $=0,05$ ditentukan sebagai berikut:

1) thitung < t tabel, maka $\mathrm{H} 0$ diterima

2) t hitung > t tabel, maka HO ditolak

\section{Koefisien determinasi $\left(\mathbf{R}^{2}\right)$}

Koefisien determinasi $\left(\mathrm{R}^{2}\right)$ dimaksud untuk mengetahui tingkat ketepatan paling dalam analisis regresi dimana hal yang ditunjukan oleh besarnya koefisien determinasi $\left(\mathrm{R}^{2}\right)$ antara 0 (nol) dengan 1 (satu). Apabila Koefisien determinasi nol, variabel independent sama sekali tidak berpengaruh terhadap variabel dependent. Apabila koefisien determinasi semakin mendekati satu, maka dapat dikatakan bahwa variabel independent berpengaruh terhadap variabel dependent, selain itu koefisien determinasi dipergunakan untuk mengetahui persentase perubahan varibel tidak bebas, yaitu Kepuasan Pelanggan (Y) yang disebabkaan oleh variabel bebas yaitu Nilai Pelanggan $\left(\mathbf{X}_{\mathbf{1}}\right)$ dan Citra Merek $\left(\mathbf{X}_{\mathbf{2}}\right)$.

\section{ANALISIS DAN PEMBAHASAN \\ Karakteristik Responden}

Semua kuesioner layak untuk diolah, responden tersebut dapat dikelompokkan berdasarkan jenis kelamin, umur, pekerjaan, pendapatan perbulan, alasan, dan kebiasaan, dan sudah pernah menjadi konsumen rumah makan lamun ombak Padang. Pengelompokan tersebut akan dijelaskan pada tabel.

\section{Jenis Kelamin}

Berdasarkan analisis yang dilakukan, maka responden dapat dikelompokkan sebagai berikut :

\section{Tabel 2}

Jumlah Responden Menurut Jenis Kelamin

\begin{tabular}{|l|c|r|rr|}
\hline No & Jenis Kelamin & Frequensi & Persentase (\%) \\
\hline 1 & Laki-laki & 54 & 54.0 \\
\hline 2 & Perempuan & 46 & 46.0 \\
\hline & Total & $\mathbf{1 0 0}$ & $\mathbf{1 0 0}$ \\
\hline
\end{tabular}

Sumber : Data Primer (Olahan), 2016

Berdasarkan tabel 2 diatas dapat dilihat jumlah responden yang mengisi kuesioner penelitian ini terdiri dari 54 orang (54\%) laki-laki dan 46 orang (46\%) perempuan. Data tersebut menggambarkan bahwa perbandingan konsumen rumah makan lamun ombak Padang berjenis kelamin laki-laki lebih banyak dari pada perempuan.

\section{Umur}

Berdasarkan analisis yang dilakukan, maka responden dapat dikelompokkan sebagai berikut: 
Tabel 3

Jumlah Responden Menurut Umur

\begin{tabular}{|l|l|l|l|}
\hline No & Umur & Frequensi & Persentase (\%) \\
\hline 1 & $\leq 20$ tahun & 4 & 4.0 \\
\hline 2 & $21-30$ tahun & 58 & 58.0 \\
\hline 3 & $31-40$ tahun & 25 & 25.0 \\
\hline 4 & $41-50$ tahun & 10 & 10.0 \\
\hline 5 & $\geq 50$ tahun & 3 & 3.0 \\
\hline & Total & 100 & 100 \\
\hline
\end{tabular}

Sumber : Data Primer (Olahan), 2016

Berdasarkan umur para responden yang mengisi kuesioner, pada tabel 3 dapat dilihat bahwa sebagian besar responden yang mengisi kuesioner adalah yang berumur antara $\leq 20$ tahun sebanyak 4 orang (4\%) dan yang berumur $21-30$ tahun yaitu sebanyak 58 orang $(58 \%)$ sedangkan responden dengan kisaran umur 31 - 40 tahun sebanyak 25 orang $(25 \%)$ dan 41 - 50 tahun sebanyak 10 orang $(10 \%)$. sedangkan responden $\geq 50$ tahun sebanyak 3 orang $(3 \%)$ konsuman rumah makan lamun ombak Padang lebih banyak umur berkisar 21 - 30 tahun karena pada umur tersebut lebih melakukan makan diluar rumah.

\section{Uji Validitas Variabel Nilai Pelanggan $\left(\mathbf{X}_{1}\right)$}

Tabel 4

Uji validitas variabel bebas nilai pelanggan $(x 1)$

\begin{tabular}{|l|l|l|c|c|}
\hline Variabel & Indikator & item & Uji Validitas & Ket \\
\hline \multirow{3}{*}{$\begin{array}{l}\text { Nilai } \\
\text { Pelanggan }\end{array}$} & \multirow{4}{*}{ Produk } & 1 & 0.708 & Valid \\
\cline { 2 - 5 } & & 2 & 0.668 & Valid \\
\cline { 2 - 5 } & \multirow{2}{*}{ Pelayanan } & 4 & 0.625 & Valid \\
\cline { 2 - 5 } & & 5 & 0.560 & Valid \\
\cline { 2 - 5 } & \multirow{2}{*}{ Harga } & 7 & 0.672 & Valid \\
\cline { 2 - 5 } & & 8 & 0.418 & Valid \\
\hline
\end{tabular}

Sumber : data primer di olah (2016)

Berdasarkan tabel 4 setelah diuji kembali untuk indikator 3, 6 dan 8 di hilangkan maka dapat dilihat bahwa semua item pernyataan dinyatakan valid karena $r$ tabel pada semua item pernyataan $r$ kritis berada diatas 0.36 . Sehingga semua item indikator dinyatakan valid.

Validitas Variabel Bebas Citra Merek $\left(\mathrm{X}_{2}\right)$

\section{Tabel 5}

Uji validitas variabel bebas citra merek $\left(\mathrm{X}_{2}\right)$

\begin{tabular}{|c|l|c|c|c|}
\hline Variabel & \multicolumn{1}{|c|}{ indikator } & item & Uji validitas & Ket \\
\hline \multirow{3}{*}{ Citra merek } & \multirow{2}{*}{ Citra perusahaan } & 1 & 0.461 & Valid \\
\cline { 2 - 5 } & & 2 & 0.403 & Valid \\
\cline { 2 - 5 } & Citra konsumen & 4 & 0.419 & Valid \\
\cline { 2 - 5 } & Citra produk & 6 & 0.525 & Valid \\
\cline { 2 - 5 } & & 7 & 0.548 & Valid \\
\hline
\end{tabular}

Sumber : Data Primer Di olah (2016)

Berdasarkan tabel 5 setelah dilakukan pengujian kembali maka dapat dilihat bahwa semua item pernyataan dinyatakan valid karena $r$ tabel pada semua item pernyataan $\mathrm{r}$ kritis berada diatas 0.36 . Sehingga semua item tersebut dinyatakan valid. 
Validitas Variabel Terikat Kepuasan Pelanggan (Y)

Tabel 6

Uji validitas variabel terikat kepuasan pelanggan (y)

\begin{tabular}{|c|c|c|c|c|}
\hline Variabel & Indikator & Item & Uji validitas & ket \\
\hline \multirow[t]{13}{*}{ Kepuasan pelanggan } & \multirow{4}{*}{$\begin{array}{c}\text { Kepuasan Atas } \\
\text { Profesional Karyawan }\end{array}$} & 1 & 0.776 & Valid \\
\hline & & 2 & 0.665 & Valid \\
\hline & & 3 & 0.522 & Valid \\
\hline & & 4 & 0.550 & Valid \\
\hline & \multirow{3}{*}{$\begin{array}{l}\text { Kepuasan Atas Daya } \\
\text { Tanggap }\end{array}$} & 5 & 0.460 & Valid \\
\hline & & 6 & 0.385 & Valid \\
\hline & & 7 & 0.467 & Valid \\
\hline & \multirow[t]{3}{*}{ Keberadaan Pelayanan } & 8 & 0.438 & Valid \\
\hline & & 9 & 0.447 & Valid \\
\hline & & 10 & 0.397 & Valid \\
\hline & \multirow[t]{3}{*}{ Kepuasan Menyeluruh } & 11 & 0.478 & Valid \\
\hline & & 12 & 0.492 & Valid \\
\hline & & 13 & 0.708 & Valid \\
\hline
\end{tabular}

Sumber : data primer di olah (2016)

Berdasarkan tabel 6 setelah diuji kembali maka dapat dilihat bahwa semua item pernyataan di atas corrected item - total correlation, maka semua indikator dinyatakan valid karena $\mathrm{r}$ tabel pada semua item pernyataan $\mathrm{r}$ kritis berada di atas 0.36 .

\section{Uji Reliabilitas}

Uji reliabilitas adalah tinngkat kestabilan dari suatu alat ukur dalam mengukur suatu gejala. reliabilitas berkenaan dengan derajat kosistensi dan stabilitas data atau temuan. Dalam pandangan positivistik (kuantitatif), suatu data dinyatakan reliabel apabila dua atau lebih peneliti dalam objek yang sama menghasilkan data yang sama, atau peneliti sama dalam waktu yang berbeda menghasilkan data yang sama atau sekelompok data bila dipecah menjadi dua menunjukan data yang tidak berbeda (sugiyono, 2013)

\section{Tabel 7}

Hasil uji reliabilitas

\begin{tabular}{|l|c|c|}
\hline \multicolumn{1}{|c|}{ Variabel } & Cronbach's Alpha & Ket \\
\hline Nilai pelanggan & 0.748 & Reliabel \\
\hline Citra merek & 0.689 & Reliabel \\
\hline Kepuasan pelanggan & 0.725 & Reliabel \\
\hline
\end{tabular}

Sumber : data primer diolah (2016)

Berdasarkan tabel 4.13 didapat angka statistik yang lebi besar dari 0.60 yang berarti 100 kuisioner yang telah disebarkan pada responden telah mendapat jawaban yang mendukung untuk melakukan penelitian selanjutnya.

Dari hasil analisis tabel 7 diatas dapat disimpulkan bahwa pada pengujian reliabilitas nilai cronbach alpha seluruh item pertanyaan berada diatas $>0,60$ sehingga seluruh item pertanyaan dinyatakan reliabel. 


\section{Uji Normalitas}

Berdasarkan pada perhitungan (terlampir), dapat diketahui bahwa uji normalitas yang diperoleh adalah sebagai berikut:

Tabel 8

Uji normalitas

One-Sample Kolmogorov-Smirnov Test

\begin{tabular}{|ll|r|}
\hline & & Unstandardized Residual \\
\hline N & & 100 \\
Normal Parameters & Mean & .0000000 \\
& Std. Deviation & 2.47335967 \\
Most Extreme Differences & Absolute & .063 \\
& Positive & .063 \\
& Negative & -.048 \\
Kolmogorov-Smirnov Z & & .626 \\
Asymp. Sig. (2-tailed) & & .828 \\
\hline
\end{tabular}

a. Test distribution is Normal.

b. Calculated from data.

Berdasarkan tabel 8 dapat kita lihat di atas diketahui bahwa nilai signifikansi sebesar $0.828>$ dari 0.05 , sehingga dapat disimpulkan bahwa data yang uji berdistribusi normal.

\section{Uji Multikolinearitas}

Tabel 9

Uji analisis multikolinearitas Coefficients $^{\mathrm{a}}$

\begin{tabular}{|l|c|c|c|c|}
\hline \multirow{2}{*}{ Model } & \multirow{2}{*}{$\mathrm{t}$} & \multicolumn{2}{|c|}{ Collinearity Statistics } \\
\cline { 4 - 5 } & $\mathrm{t}$ & Sig. & Tolerance & VIF \\
\hline 1(Constant) & 1.031 & .305 & & 1.428 \\
NILAI PELANGGAN (X1) & 8.323 & .000 & .700 & 1.428 \\
CITRA MEREK (X2) & 2.791 & .006 & .700 & \\
\hline
\end{tabular}

a. Dependent Variable : KEPUASAN PELANGGAN (Y)

Dari tabel 9 di atas diketahui bahwa VIF dari nilai pelanggan < dari nilai VIF yang ditentukan sebesar 10, sehingga diduga untuk variabel tersebut dalam model regresi tidak terdapat persoalan multikolinearitas. 
Tabel 10

Uji heteroskedastisitas

\begin{tabular}{|c|c|c|c|c|c|}
\hline \multicolumn{6}{|c|}{ Coefficients $^{a}$} \\
\hline \multirow[b]{2}{*}{ Model } & \multicolumn{2}{|c|}{ Unstandardized Coefficients } & \multirow{2}{*}{$\begin{array}{c}\begin{array}{c}\text { Standardized } \\
\text { Coefficients }\end{array} \\
\text { Beta }\end{array}$} & \multirow[b]{2}{*}{$\mathrm{t}$} & \multirow[b]{2}{*}{ Sig. } \\
\hline & B & Std. Error & & & \\
\hline 1 (Constant) & 4.296 & 3.532 & & 1.216 & .227 \\
\hline $\begin{array}{l}\text { CITRA } \\
\text { MEREK (X2) }\end{array}$ & .011 & .117 & .012 & .096 & .924 \\
\hline $\begin{array}{l}\text { NILAI } \\
\text { PELANGGA } \\
\mathrm{N}(\mathrm{X} 1)\end{array}$ & -.070 & .080 & -.105 & -.871 & .386 \\
\hline
\end{tabular}

Berdasarkan tabel $10 \mathrm{di}$ atas dapat kita lihat bahwa nilai signifikansi variabel citra merek (x2) sebesar 0.924 lebih besar dari 0.05 itu berarti variabel citra merek $(\mathrm{x} 1)$ tidak terjadi heteroskedastisitas. Sementara itu diketahui nilai signifikasi variabel nilai pelanggan (x1) sebesar 0.386 lebih besar dari 0.05 artinya tidak terjadi heteroskedastisitas pada variabel nilai pelanggan.

\section{Analisis Regresi Berganda}

Tabel 11

Uji analisis regresi berganda

Coefficients $^{\mathrm{a}}$

\begin{tabular}{|c|c|c|c|c|c|}
\hline \multirow[b]{2}{*}{ Model } & \multicolumn{2}{|c|}{$\begin{array}{l}\text { Unstandardized } \\
\text { Coefficients }\end{array}$} & \multirow{2}{*}{$\begin{array}{c}\begin{array}{c}\text { Standardized } \\
\text { Coefficients }\end{array} \\
\text { Beta }\end{array}$} & \multirow[b]{2}{*}{$\mathrm{t}$} & \multirow[b]{2}{*}{ Sig. } \\
\hline & B & Std. Error & & & \\
\hline 1 (Constant) & 6.384 & 6.192 & & 1.031 & .305 \\
\hline $\begin{array}{l}\text { NILAI } \\
\text { PELANGGAN } \\
(\mathrm{X} 1)\end{array}$ & 1.172 & .141 & .638 & 8.323 & .000 \\
\hline $\begin{array}{l}\text { CITRA MEREK } \\
\text { (X2) }\end{array}$ & .574 & .206 & .214 & 2.791 & .006 \\
\hline
\end{tabular}

a. Dependent Variable: KEPUASAN PELANGGAN $(\mathrm{Y})$

Berdasarkan analisis data dengan menggunakan program SPSS 17.0 for Windows, maka diperoleh persamaan regresi sebagai berikut :

$$
\mathrm{Y}=6.384+1.172 \mathrm{x} 1+0.574 \times 2+\mathrm{e}
$$

Dimana:

$$
\begin{array}{ll}
\mathrm{a} & =\text { Konstanta } \\
\mathrm{Y} & =\text { Kepuasan Pelanggan } \\
\mathrm{X}_{1} & =\text { Nilai pelanggan } \\
\mathrm{X}_{2} & =\text { Citra merek } \\
\mathrm{e} & =\text { Error }
\end{array}
$$

Dari persamaan diatas dapat dijelaskan nilai koefisiean regresi dari masing - masing variabel bebasnya dapat dijelaskan sebagai berikut:

1. Konstanta sebesar 6.384, artinya jika nilai pelanggan (x1) dan citra merak (x2) nilainya 0 , makabesar output kepuasan pelanggan (y) adalah 6.384 .

2. Koefisien regresi variabel nilai pelanggan sebesar 1.172 artinya jika nilai pelanggan mengalami keanikan satu satuan, maka kepuasan pelanggan akan 
mengalami peningkatan sebesar 1.172 satuan dengan asumsi variabel lainnya bernilai tetap.

3. Koefisien regresi variabel citra merek sebesar 0.574 ,artinya jika citra merek mengalami kenaikan satu satuan, maka kepuasan pelanggan akn mengalami kenaikan sebesar 0.574 satuan dengan asumsi variabel independen lainnya bernilai tetap.

\section{Uji T}

\section{Tabel 12}

Uji hipotesis T Coefficients $^{\mathrm{a}}$

\begin{tabular}{|l|c|c|c|c|c|}
\hline & \multicolumn{2}{|c|}{ Unstandardized Coefficients } & \multicolumn{2}{c|}{$\begin{array}{c}\text { Standardized } \\
\text { Coefficients }\end{array}$} & \\
\cline { 2 - 4 } \multicolumn{1}{c|}{ Model } & $\mathrm{B}$ & Std. Error & Beta & $\mathrm{T}$ & Sig. \\
\hline 1 (Constant) & 6.384 & 6.192 & & 1.031 & .305 \\
$\quad \begin{array}{l}\text { NILAI } \\
\text { PELANGGAN (X1) }\end{array}$ & 1.172 & .141 & .638 & 8.323 & .000 \\
$\begin{array}{l}\text { CITRA MEREK } \\
\text { (X2) }\end{array}$ & .574 & .206 & .214 & 2.791 & .006 \\
\hline
\end{tabular}

a. Dependent Variable: KEPUASAN PELANGGAN (Y)

Hipotesis dalam penelitian ini adalah variabel nilai pelanggan berpengaruh positif dan signifikan terhadap kepuasan pelanggan dan variabel citra merek berpengaruh positif dan signifikan terhadap kepuasan pelanggan. Berdasarkan Tabel 4.23 diketahui bahwa nilai koefisien dari variabel nilai pelanggan bernilai positif 8,323 dan citra merek bernilai 2.791 dan nilai t hitung adalah sebesar 1.031 dengan signifikan $0,000<0,05$. Hal ini berarti variabel nilai pelanggan dan citra merek berpengaruh positif dan signifikan terhadap kepuasan pelanggan. Sehingga dapat dikatakan bahwa hipotesis dapat diterima.

\section{Uji F}

Tabel 13

\section{Uji hipotesis F} ANOVA $^{\mathrm{D}}$

\begin{tabular}{|c|c|c|}
\hline Model & $\mathrm{F}$ & Sig. \\
\hline $\begin{array}{ll}1 \text { Regression } \\
\text { Residual } \\
\text { Total }\end{array}$ & 73.201 & $.000^{\mathrm{a}}$ \\
\hline
\end{tabular}

a. Predictors: (Constant), CITRA MEREK (X2), NILAI PELANGGAN (X1)

b. Dependent Variable: KEPUASAN PELANGGAN (Y)

Berdasarkan hasil uji ANOVA atau F test pada tabel didapatkan $\mathrm{F}$ hitung sebesar 73.201 dengan tingkat signifikansi 0,000. Karena tingkat signifikansi $0,000<0,05$ maka model regresi dapat digunakan untuk memprediksi kepuasan pelanggan $(\mathrm{Y})$ atau dikatakan bahwa variabel nilai pelanggan $(\mathrm{x} 1)$ dan citra merek (x2), secara bersama-sama atau simultan berpengaruh signifikan terhadap variabel kepuasan pelanggan $(\mathrm{Y})$. 


\section{Analisis Koefisien Determinasi $\left(\mathbf{R}^{2}\right)$}

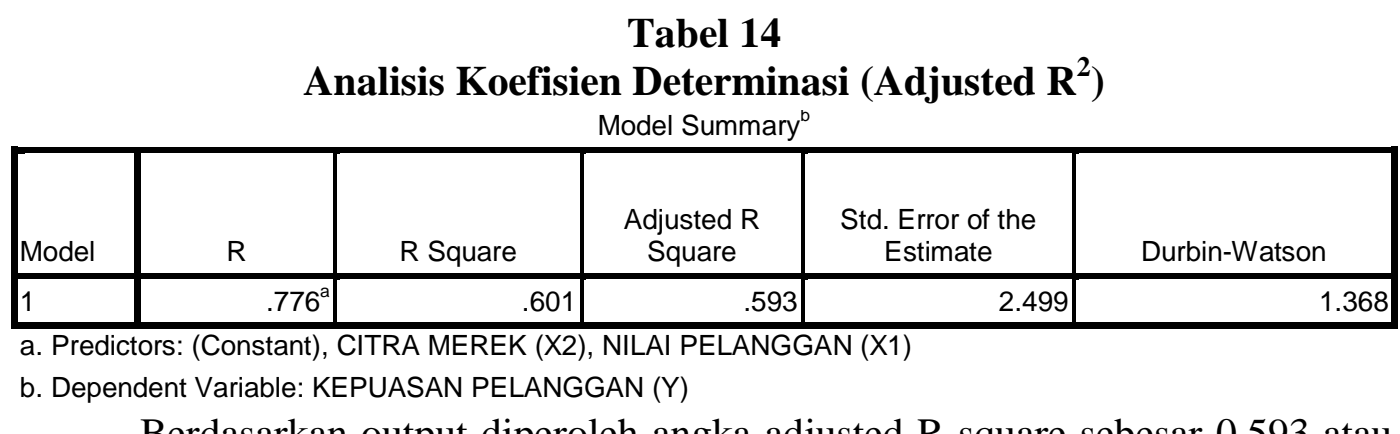

Berdasarkan output diperoleh angka adjusted R square sebesar 0.593 atau 59.3\%.hal ini menunjukan bahwa persentase sumbangan pengaruh variabel independen yaitu nilai pelanggan dan citra merek terhadap kepuasan pelanggan $59.3 \%$,atau variasi variabel bebas yang digunakan dalam model mampu menjelaskan sebesar $59.3 \%$ variasi variabel dependen.sedangkan sisanya sebesar $41.7 \%$ dipengaruhi oleh variabel lain yang tidak dimasukan dalam model penelitian ini.

Pengaruh Nilai Pelanggan $\left(X_{1}\right)$ terhadap kepuasan pelanggan $(y)$

Dalam penelitian ini adalah variabel nilai pelanggan berpengaruh positif dan signifikan terhadap kepuasan pelanggan. Berdasarkan Tabel 4.23 diketahui bahwa nilai koefisien nilai pelanggan bernilai positif 1,172 dan nilai t hitung adalah sebesar 1.031 dengan signifikan $0,000<0,05$. Hal ini berarti variabel nilai pelanggan berpengaruh positif dan signifikan terhadap kepuasan pelanggan. Sehingga dapat dikatakan bahwa hipotesis dapat diterima.

Berdasarkan hasil uji ANOVA atau F test pada tabel 4.26 didapatkan F hitung sebesar 73.201 dengan tingkat signifikansi 0,000. Karena tingkat signifikansi $0,000<0,05$ maka model regresi dapat digunakan untuk memprediksi kepuasan pelanggan (Y) atau dikatakan bahwa variabel nilai pelanggan (X), secara bersama - sama atau simultan berpengaruh signifikan terhadap variabel kepuasan pelanggan (Y).

Penelitian Balqis Diaab, (2009) Tentang Analisis Pengaruh Nilai Pelanggan Dan Citra Merek Terhadap Terhadap Kepuasan Pelanggan Dalam Meningkatkan Retensi Pelanggan (studi kasus pada gies batik pekalongan), dimana hasil penelitian terhadap pengaruh nilai pelanggan positif dan signifikan terhadap kepuasan pelanggan.

Penelitian Rahmat Hidayat, (2009) Tentang Pengaruh Kualitas Layanan,Kualitas Produk Dan Nilai Nasabah Terhadap Kepuasan Dan Loyalitas Nasabah Bank Mandiri, dimana hasil penelitian terhadap pengaruh nilai pelanggan positif dan signifikan terhadap kepuasan pelanggan.Dari beberapa penelitian di atas maka dapat ditarik hipotesis :

$\mathrm{H}_{1}$ : Diduga Nilai Pelanggan berpengaruh signifikan dan positif terhadap kepuasan pelanggan

\section{Pengaruh Citra Merek $\left(\mathrm{X}_{2}\right)$ Terhadap Kepuasan Pelanggan ( $\left.\mathrm{Y}\right)$}

Dalam penelitian ini adalah variabel citra merek berpengaruh positif dan signifikan terhadap kepuasan pelanggan. Berdasarkan Tabel 4.23 diketahui bahwa nilai koefisien citra merek bernilai positif 0,574 dan nilai t hitung adalah sebesar 
1.031 dengan signifikan $0,000<0,05$. Hal ini berarti variabel citra merek berpengaruh positif dan signifikan terhadap kepuasan pelanggan. Sehingga dapat dikatakan bahwa hipotesis dapat diterima.

Penelitian Balqis Diaab, (2009) Tentang Analisis Pengaruh Nilai Pelanggan Dan Citra Merek Terhadap Terhadap Kepuasan Pelanggan Dalam Meningkatkan Retensi Pelanggan (studi kasus pada gies batik pekalongan), dimana hasil penelitian terhadap pengaruh nilai pelanggan positif dan signifikan terhadap kepuasan pelanggan.

Penelitian Mohammad Tambrin, (2010) tentang Pengaruh Brand Image Pelanggan Kartu Simpati Terhadap Kepuasan Mahasiswa Universitas Trunjoyo Madura, dimana hasil penelitian terhadap pengaruh nilai pelanggan positif dan signifikan terhadap kepuasan pelanggan.Dari beberapa penelitian di atas maka dapat ditarik hipotesis :

$\mathrm{H}_{2}$ : Diduga Citra merek berpengaruh signifikan dan positif terhadap kepuasan pelanggan

\section{SIMPULAN} bahwa :

Berdasarkan hasil penelitian yang dilakukan maka dapat disimpulkan

1. Variabel nilai pelanggan berpengaruh terhadap kepuasan pelanggan rumah makan lamun ombak. hal ini mengindikasikan bahwa nilai pelanggan merupakan hal utama yang dilihat oleh konsumen dalam memutuskan kepuasan pelanggan. nilai pelanggan memiliki pengaruh dalam kepuasan pelanggan.

2. Variabel citra merek berpengaruh terhadap kepuasan pelanggan rumah makan lamun ombak. hal ini mengindikasikan bahwa citra merek merupakan variabel yang dilihat oleh konsumen dalam memutuskan kepuasan pelanggan. citra merek memiliki pengaruh dalam keputusan kepuasan pelanggan untuk memilih tempat makan yang menarik hati konsumen.

\section{DAFTAR PUSTAKA}

Berry, Leonard L And Parasuraman,A Zeithaml.1991.Marketing Service :Competing Through Quality.New York : The Free Press

Diab, Balqis 2009, Analisis Pengaruh Nilai Pelanggan Dan Citra Merek Terhadap Kepuasan Pelanggan Dalam Meningkatkan Retensi Pelanggan (Studi Kasus Pada Gies Batik Pekalongan). Tesis : Universitas Diponegoro.

Dessy Amalia Rahayu,2011.judul skripsi "Pengaruh Nilai Pelanggan, Kepercayaan, Dan Kualitas Layanan Terhadap Kepuasan Pelanggan Dan Loyalitas Pelanggan Penyedia Layanan Jasa Internet Di Kecamatan Sumbersari"

Hanggadhika, Hardian. 2010. Judul penelitian ”Analisis Pengaruh Ekuitas Merek. 
Hidayat, Rahmad .2009 Pengaruh Kualitas Layanan, Kualitas Produk Dan Nilai Nasabah Terhadap Kepuasan Dan Loyalitas Nasabah Bank Mandiri. Jurnal Manajemen Dan Kewirausahawan . Vol 11 No. 1

Ilham, Ilham Hendra. 2008. Pengaruh Penerapan Strategi Customers Relationship Marketing Terhadap Kepuasan Nasabah Pt. Bank Negara Indonesia (Persero) Tbk Kantor Cabang Bukit Tinggi. Skripsi : Universitas Andalas

Iqbal, Hasan, 2008.Pokok-Pokok Materi Statistik 2(Statistik Inferensif) Edisi 2. Jakarta : Bumi Aksara

Jaya, R. S., \& Susanti, F. (2019). Pegaruh Integrated Marketing Communication Terhadap Brand Equity Pada Mc Donalds A.Yani Padang. https://doi.org/10.31227/osf.io/4ebk2

Jogiyanto, H.M. 2004, Metodologi Penelitian Bisnis : Salah Kaprah Dan Pengalaman - Pengalaman, Edisi 1 . Yogjakarta:Bpfe

Kotler, Philip.2000,Manajemen Pemasaran, Analisis Perencanaan, Implementasi Dan Kontrol. Edisi Kesembilan. Terjemahan Hendra Teguh Se,Akt Dan Roni A Rusli Se,Ak. Jakarta :Precentice Hall Inc

Kevin Keller, 2009.Manajemen Pemasaran, Edisi 12. Jilid 1 Jakarta : 1 Pt Indeks

Kelvin Keller, 2009. Manajemen Pemasaran Edisi 12 Jilid 2. Jakarta : Pt Indeks Moween, Mayer Dan Minor Kent. 2001, Analisis Perilaku Konsumen Dan Faktor-Faktor Yang Mempengaruhi. Edisi Terjemahan, Jakarta : Rieneka Cipta

Marlius, D. (2018). Pengaruh Dimensi Kualitas Pelayanan Website Akademik Terhadap Kepuasan Mahasiswa Pada STIE “KBP”. Jurnal Ipteks Terapan. $\begin{array}{lllll}\text { Volume } & 12 . & \text { No. } & 2 . & \text { Hal. }\end{array}$ http://doi.org/10.22216/jit.2018.v12i2.633

Mayliza, R. (2019). Pengaruh Citra Perusahaan (Corporate Image) Dan Penanganan Keluhan (Complaint Handling) Terhadap Loyalitas Pelanggan (Loyality) Natasha Skin Care Di Kota Padang. https://doi.org/10.17605/OSF.IO/DF9XJ

Mayliza, R. (2019). Pengaruh Kesadaran Merek, Asosiasi Merek Dan Perception Of Quality Terhadap Keputusan Pembelian Hospital Bed Merek Paramout Di PT. Aga Medika Utama Padang (Studi Kasus Rumah Sakit Umum Kota Padang). https://doi.org/10.17605/OSF.IO/VYQ4E 
Meria Widiastuti,2012. Judul Skripsi “Analisis Pengaruh Nilai Pelanggan Dan Citra Merek Terhadap Kepuasan Pelanggan Pada Restoran Sederhana Di Kota Padang".

Mulyadi, 2005. Sistem Manajemen Strategik Berbasis Balanced Score Card. Yogyakarta : Upp Amp Ykpn

Nazir, Moh, 2005. Metodologi Penelitian. Bogor : Ghalia Indonesia Parasuraman, A, Et Al (1985), A Conceptual Modal Of Service Quality And Its Implications For Future Research, Jurnal Of Marketing.Vol 49 (Fall).Hal 44

Pranata, H. I., \& Mayliza, R. (2019). Pengaruh Komunikasi Pemasaran Terpadu Dan Ekuitas Merek Terhadap Loyalitas Konsumen Pada CV. Laris Motor Cabang Air Haji. https://doi.org/10.31219/osf.io/d9qsu

Priyatno,Duwi,2011.Buku Saku Spss (Analisis Statistika Data, Lebih Cepat,Efisien Dan Akurat). Yogyakarta : Media Kom Purnama, Abdi 2007. Analisis Perbandingan Tingkat Kepuasaan Pelanggan Perusahaan Air Line (Studi Kasus : Dalam Adam Air,Air Asia,Dan Lion Air).Skripsi : Universitas Andalas

Ricardo, Toni,2007. Persepsi Pelanggan Terhadap Costomer Value (Nilai - Nilai Pelanggan) Pada Rumah Makan Padang (Studi Pada Berbagai Rumah Makan Di Bukit Tinggi). Skripsi : Fakultas Ekonomi Unand

Sari, Evi Thelia. 2006.Peranan Customer Velue Dalam Memepertahan Ke Unggulan Keunggulan Bersaing Pada Restoran Cepat Saji.Jurnal Manajemen Perhotelan. Vol 2, No 2 Hal 67 - 75

Saryadi Dan Wahyuddin,M. 2006 Analisis Nilai Kepuasan Pelanggan Kendaraan Bermotor Roda 2 Di Surakarta (Studi Kasus Sepeda Motor Bebek Merek Honda)

Sekaran, Uma. 2006. Metodologi Penelitian untuk Bisnis , Edisi 4. Jakarta : Salemba Empat

Simamora, Bilson, 2002. Paduan Riset Perilak Konsumen, Jakarta Pt Gramedia Pustaka Utama

Sugiono 2004.Metode Penelitian Bisning. Bandung : Alfabeta

Sutrisno, 2006.Analisa Pengaruh Perilaku Konsumen Dan Nilai Konsumen Terhadap Strategi Pemasaran Produk Pasta Gigi Putih Medium Di Area Pemasaran Surabaya (Studi Kasus Produk Pasta Gigi Putih Medium 
Ukuran 75 Gram Produksi Pt Unilevers Indonesia, Rungkut -Surabaya). Tesis : Institut Teknologi Sepuluh November.

Thambrin, Mohammad.2010. Pengaruh Brand Image Pelanggan Kartu Simpati Terhadap Kepuasan Mahasiswa Universitas Trunojoyo Madura. Jurnal Studi Manajemen.Vol 4 No 1

Tjiptono, Fandi, 1997.Strategi Pemasaran Yogyakarta : Andi Offset

Tjiptono, 2005. Manajemen Pemasaran Jasa, Malang : Bayu Media

Umar, Husein. 2005.Risset Pemasaran Dan Perilaku Konsumen. Jakarta : Pt Gramedia Pustaka Utama. Http://Aratunawar.Wordpress.Com. Pemasaran Jasa 